\title{
Diffusing Best Practices: A Design Science Study Using the Theory of Planned Behavior
}

\author{
Richard Baskerville ${ }^{1}$ and Jan Pries-Heje ${ }^{2}$ \\ ${ }^{1}$ Georgia State University, USA \\ Baskerville@acm. org \\ ${ }^{2}$ Roskilde University, Denmark \\ janph@ruc.dk
}

\begin{abstract}
Both the practice and the research literature on information systems attach great value to the identification and dissemination of information on "best practices". In the philosophy of science, this type of knowledge is regarded as technological knowledge because it becomes manifest in the successful techniques in one context. While the value for other contexts is unproven, knowledge of best practices circulates under an assumption that the practices will usefully self-diffuse through innovation and adoption in other contexts. We study diffusion of best practices using a design science approach. The study context is a design case in which an organization desires to diffuse its best practices across different groups. The design goal is embodied in organizational mechanisms to achieve this diffusion. The study used Theory of Planned Behavior (TPB) as a kernel theory. The artifacts resulting from the design were twoday training workshops conceptually anchored to TBP. The design theory was evaluated through execution of eight diffusion workshops involving three different groups in the same company. The findings indicate that the match between the practice and the context materialized in the presence of two concordant factors. On the context side, the qualities of the selected opinion leader were necessary to provide the subjective norm described in TPB. On the best practice side, the technological qualities of the best practice itself were necessary to instill the ideal attitude (belief that the behavior will be effective). These two factors were especially critical if the source context of the best practice is qualitatively different from the target context into which the organization is seeking to diffuse the best practice.
\end{abstract}

Keywords: Diffusion, Best Practice, Theory of Planned Behavior, Action Case.

\section{Introduction}

While there is much work regarding the content of best practices, there is remarkably little work that considers that nature of best practices and in particular the diffusion of best practices in general. The definition of the concept best practice is regarded as subjective. The term is rarely defined in the literature. For the purposes of this paper, we will adopt the following as our working definition, "best practices are leadership, management, or operational methods or approaches that lead to exceptional performance." [1, p. 334] 
This general conceptualization of best practices is flavored by its anchors to the concepts of professionalism. Professionals encourage the diffusion of best practices among their professional colleagues. Often this encouragement takes the form of professional certifications or accreditation. While accreditation, such as professional accreditation, is often intended to diffuse best practices. However, studies have shown that it actually has only limited effects in this regard [2]. Such studies suggest a critical suspicion of the concept of best practice diffusion might be fair.

Diffusion of best practices by professionals is sometimes driven by commercial interests. Commercial pressure to converge on a set of best practices in global strategic management arises from international competition and capital markets. Improved communications and professionalization often presses for dissemination of best practices worldwide. However, this idea downplays differences in national systems and cultures as sources of competitive advantage. More nuanced strategy formulation is necessary that a radical convergence on a single, global set of best practice [3]. Such differences, and the need for nuanced diffusion of best practices, may help explain why the effects of professional diffusion of best practices are so limited.

The need for professionals to adapt or "nuance" the best practices as they diffuse is a continuing theme in the research in this area. Consultants and experts deliver practices to their companies and their clients. These professionals operate with conflicting roles, creating a dilemma. In one role, as professionals, they adhere to an epistemic community; in another, they adhere to a community of practice [4]. Professionals enacting a role as an expert interacts more with their epistemic community, privileging their creative processes. To convey the value of these proposed best practices, the professional must convince top management to change their strategic vision. Professionals enacting the role as a consultant interacts more with their community of practice, privileging the diffusion of best practices across the firm to enhance routine operations. These professionals (consultants and experts) often operate globally. As a result, any diffusion of best practices can involve inter-industries, cross-cultural, international, inter-disciplinary and trans-disciplinary links [4]. Professionals are knowledge carrying agents who diffuse best practices into diverse organizations.

Sluggish diffusion of best practices can sometimes be explained simply. For example, diffusion is known to increase "when the actors involved are perceived as being similar, when the diffusing practices are theorized as similar, and when the practices are theorized to be modern." [5] But the conceptualization of diffusion of best practices can be overly naïve. Best practice diffusion often involves a dependence upon the transfer of primarily explicit knowledge. Many professionals admit that such explicit coding of a best practice will lack its important implicit aspects. Such explicit best practices may provide a foundation for practicing in the setting at hand, but adaptation is usually necessary. Consequently, in real-world usage, a best practice will incorporate an emergent property. A coded best practice represents the starting point for a process of improvement [6]. In this sense, diffusion of best practices is not necessarily dissemination of knowledge. Rather it is a process of improvement. In this process, the actors in the field are not just receivers of a best practice, but are co-constructors of this best practice. In other words, the best practice must be co-constructed by the actors in the new context [7].

The need for best practice co-construction in the diffusion process means that certain kinds of best practices may seem to diffuse more easily than others. For example, 
with reference to new product development, best practices for strategy-setting (product selection, goal-setting, technology, etc.) seem to diffuse more widely than best practices for control (process control, metrics, documentation, etc.) [8]. It is not uncommon to blame limited best practice diffusion on motivational factors, like resistance to change. However, diffusion of high-value best practices are related to internal stickiness [the inability to reset a practice, 9]. Sticky best practices have a higher incremental cost of best-practice diffusion. Studies have shown that the central barriers to the diffusion of a best practice are the recipient's lack of absorptive capacity, causal ambiguity in the practice itself, and an arduous relationship between the source and the recipient [9].

The diffusion of best practices is therefore not as simple as declaring new process rules. For example, there is a known dialectical tension among the key principles in international business regulation. Harmonization and mutual recognition often oppose national sovereignty and low cost location. Such rule compliance opposes diffusion of best practices, continuous improvement, and best available technology [10].

The concept of a best practice implies a motivation to diffuse such a practice. However, the literature suggests that this diffusion is problematic. There are at least six aspects to these problems:

1. Diffusion of best practices can be motivated as part of a professional identity, and such diffusion may disregard the suitability for such practices in different settings.

2. In their efforts to diffuse best practices, experts and consultants can overly regard their own epistemic community and marginalize the community of practice that contextualizes the practices.

3. Diffusion of best practices sometimes disregards the innate advantages of national systems and cultures.

4. Best practices sometimes diffuse in an incomplete form: the explicit knowledge aspects are disseminated without the tacit knowledge aspects. New settings require adaptation, which can mean deconstructing and re-constructing/coconstructing the practice as an outcome of its arrival in a new setting with different actors.

5. Diffusion of highly valuable best practices can encounter internal stickiness making the diffusion costly.

6. Diffusion of best practices varies depending on the subject matter of the practice.

These issues lead to the research question addressed in this paper: Why do organizations fall victim to the innate problems with diffusion of best practices; how can an organization ideally enable such diffusion?

We use a design science research approach to explore this question. We develop a procedural artifact (a process or method artifact) that aims to avoid the known problems above and effectively diffuse best practices. Our kernel theory is Theory of Planned Behavior as (TPB). A kernel theory is a natural or social science theory that governs design requirements [11]. We selected TPB because the initial framing of the problem was given as resistance to change. This abductive selection arose because TPB is perhaps the most widely acknowledged model for describing the decisionmaking process that results in behavioral stasis or behavior change. (See the discussion of TPB in the next section.) We report results in a case where TPB was used as an intervention to diffuse a procedure for (improved) project management. A workshop 
was carefully designed using TPB as a basis. Forty managers in this workshop reported strongly increased intention to use immediately after the workshop. Furthermore observational data indicated a majority of the managers actually used the procedure months after the workshop.

\section{Theory of Planned Behaviour (TPB)}

TPB is a predictive model of human behavior in specific situations $[12,13]$. It is an extension of the theory of reasoned action. Ajzen is probably correct when he states, "Judging by the sheer number of investigations it has stimulated, the TPB is perhaps the most popular of the reasoned action models" [14, p. 454]. As an extension of the theory of reasoned action, TPB is anchored in the human attitude toward a behavior, often modeled as an expectancy of value. Such attitudes have a cognitive component (beliefs) and an affective component (evaluations). The causality presents actions as dependent on attitudes, and attitudes as dependent on beliefs and evaluations.

TPB regards an individual's intention to perform a given behavior as a central factor. A strong intention is expected to increase the likelihood of an actual behavior. However, the degree to which an intention leads to a behavior is conditioned by the degree to which an individual actually has volitional control (whether the individual can actually decide to perform the behavior). Behavioral achievement depends on intention (motivation) and ability (behavioral control) [15].

Behavioral control regards the extent to which people possess the information, skills, abilities, emotions, compulsions and the absence of external barriers to perform a given behavior. In TPB, the actual behavioral control is less important that the perceived behavioral control. That is, the degree of their belief in their behavioral control. It is very similar to the notion of self-efficacy. " Behavioral control is linked both to behavioral intention and behavioral achievement [14].

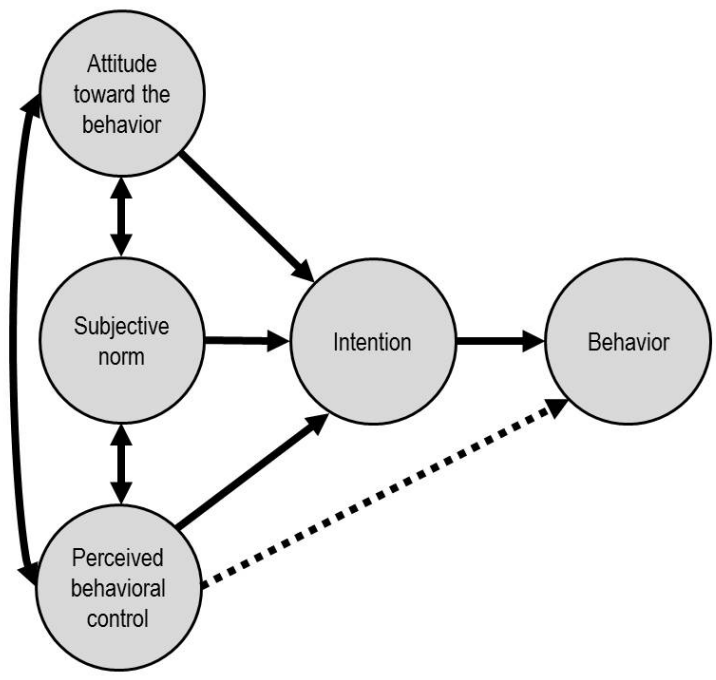

Fig. 1. Theory of Planned Behavior [from 15] 
Motivation is partly comprised of a trait possessed by the individual: a general disposition to succeed that is not dependent on the situation at hand. This general disposition combines with a situational expectancy of success. A third situational factor is the incentive value of the expected success. Together with behavioral control, these factors combine to make three determinants of behavioral intention. The first determinant is the attitude toward the behavior. It embodies the degree to which the individual has a favorable or unfavorable evaluation or appraisal of the behavior. The second determinant is subjective norm, a social factor referring to the perceived social pressure to perform or not to perform the behavior. The third determinant is perceived behavioral control [15]. Figure 1 illustrates the TPB.

\section{$3 \quad$ Research Method}

The case methodology applied here is described as an action case [16]. An action case is a hybrid research approach that combines action research and interpretive case approaches. It combines intervention and interpretation in order to achieve both change and understanding. It is a form of soft field experiment with less emphasis on iteration and learning and more on trial and making. The approach is holistic in philosophy, and prediction is not emphasized. The intervention in this case was that of a designer introducing a previously well-published theory - the theory of planned behavior (TPB) - as a strategy for solving a problem diffusing a best practice. The case at hand is a setting in which an international company in the energy sector faced problems. For anonymity reasons we will refer to this company as ENKACE.

ENKACE is an old company headquartered in Europe but working with projects all over the world. Recently ENKACE has grown considerably mainly through mergers and acquisition. They had started to gather "lessons learned" from projects and realized that improving their project management would have a huge positive influence on their results. For example, better forecasting of their potential problems through early risk management brought the potential of saving millions of Euros. Another example is better stakeholder management, which together with early communication about expectations would have saved a number of projects from costly failure.

But in some projects, ENKACE had found that everything had worked out successfully. Based on these successes, the quality department had developed a best practice procedure. This procedure was carefully written so that problems that had been encountered in ENKACE projects could have been coped with. ENKACE quality managers from all parts of the world had been involved in the development of the procedure, hence it was covering best practice in ENKACE. The first version of the best practice procedure was aimed at project managers managing energy projects at sea. Their challenge in diffusing these best practices was to improve the professionalism of some 40 project managers for at-sea operations.

One author of this paper was presented with ENKACE's best-practice diffusion problem. Using TPB as grounding, this researcher suggested the design of an intervention to deliver these best practices as ideal professional conduct for the project managers. The design idea implied within TPB is to diffuse both explicit and implicit best practice to build on the project managers general disposition to succeed. The design process began in early 2013 with a brainstorming and knowledge transfer session at ENKACE headquarters. Following the brainstorming session, the researcher 
created an initial design. This design was then discussed in several video-based sessions involving participants from ENKACE worldwide. The final design was framed as a 2-day workshop for project managers.

Data consisted of field notes and documentation. The documentation centered on the evolving design of the training program and the evaluation of the various events in the training program. Like other forms of action research, action case methodology is often iterative. In ENKACE, the iterations coincided with a sequence of training events (e.g., in Asia, Europe, and North America). Learning acquired in each event conditioned the subsequent events. Some of these training events were collaborations between a professional trainer and the researcher; other training events were conducted by the trainer alone.

\section{$4 \quad$ The Design}

The kernel theory for the design was TPB. A number of company-based examples were chosen to influence the attitude of project managers. The rationale for choosing the examples involved illustrating for the participants how unfortunate project outcomes could have been prevented or avoided by using a particular best practice (in this case, the Project Management Procedure).

Influence over subjective norms involved recruiting an influential Project Manager as a co-trainer in the workshop. This individual is seen among colleagues as a respected opinion leader. The co-trainer not only influences (group) normative beliefs in the group of project managers participating in the workshop, but also encourages others in co-construction of the best practice. Co-training by someone perceived as a peer participant can relax other participants about interactively offering content adjustments. Hence this part of the intervention was built on Rogers' Diffusion of

\section{1st Workshop Design}

First Day
1. Success and failure in projects; every
participating project manager was asked
on beforehand to think about projects
and bring examples to the workshop
2. Project thinking; that is project
management theory and exercises on
teaching case
3. Learning from projects; looking at
lessons learned from real projects with
the aim of identifying where the use of
the best practice procedure could have
avoided mistakes and problems

First Day

Fig. 2. First workshop design

\author{
Second Day \\ 4. Project Thinking; more project \\ management theory focusing on risk \\ management and on planning \\ 5. Teaching case exercise on risk \\ management \\ 6. Teaching case on mobilization and \\ deployment planning (two phases in \\ ENKACE project model that the \\ procedure covered) \\ 7. Summing up key points from \\ workshop
}


Innovations theory [17] using the idea that early adopters have the highest degree of opinion leadership.

The workshop included training in risk management, stakeholder management, and planning. This training is intended to influence perceived behavioral control. A teaching case built on realistic projects was developed. Exercises incorporated in the teaching case gives participants the feeling that they have the necessary information, skills, abilities, etc., to exercise volitional control to shape their behavior and their behavioral intentions.

See Figure 2 for the overall workshop design.

The Design Rationale behind the workshop design was the following (numbers referring to Figure 2):

1. The workshop begins with a focus on the attitude of the participating project managers. This session unfreezes the participants' attitude about their past behaviors and the behavioral norms. Attitudes are opened to the relevance of doing something different. This attitudinal shift arises in telling the failure stories from their own projects. Simultaneously participants contribute their own best practices for their peers to consider. Such a discussion of the success stories reveals implicit knowledge within the community of practice that is present in the workshop.

2. The workshop participants shift to a learning mode by studying best practices from other companies and from the professional community of project managers. This process should help move subjective norms closer to the best practices.

3. The first day concludes with a further focus on the attitude of the project managers. A sense of motivation is communicated helping participants realize that the use of the best practice procedure could have led to the prevention of unfortunate previous outcomes.

4. The second day begins with a continuation of the learning mode to help reset to subjective norms.

5. The centerpiece of the second day is a teaching case to provide the participating project managers an understanding of how they could apply the best practice in a professional way. This activity increases the belief in their behavioral control.

6. The emphasis on improving a belief in behavioral control continues. The cotrainer from ENKACE participates intensely in the discussion of the case thereby influencing both the belief in behavioral control and the subjective norm within the community of practice among ENKACE project managers. By witnessing the coconstruction of the best practice at the hands of a peer project manager (the cotrainer), the belief in behavioral control re-freezes the best practice as behavioral intention.

7. The final session of the workshop evaluates the results of the workshop process. The participants critically assess "Did it work?" and "How do you perceive the best practice procedure now?"

\subsection{Iteration One}

The first instance of the workshop was held in Asia early May 2013 primarily for Asian project managers. An author of this paper worked as the main trainer. A known 
strategy for overcoming resistance-to-change is to involve an opinion leader as a change advocate [17]. An experienced project manager - now working in Quality Assurance (QA) at ENKACE - was enlisted as co-trainer in the workshop. Before having the workshop the author and the enlisted co-trainer had a virtual meeting a month before and a physical meeting the day before the workshop. These two meetings were spend re-designing and improving the workshop. For example the meetings resulted in the specific choice of cases for learning (bullet 3 in Figure 2) and in the specific presentation of the teaching Case (bullet 5 and 6 in Figure 2).

The presence of the opinion leader as co-trainer succeeded. Commencing with the project manager's own successes and failures also succeeded in making the participants receptive to the best practice and its concomitant professional knowledge. Learning from past projects, especially a demonstration of exactly where the new best practice procedure would have helped, was also successful. The discussion of each case clearly brought forward knowledge that was not explicitly stated in the practice, but was implicitly known by the experienced members of the group.

At the end of the workshop people were enthusiastic about the best practice procedure. This practical outcome suggests that this first test run of using TPB as kernel theory for designing a workshop was a success: The participants found it useful and gave it high scores for utility.

The two next instances of the workshop were held in Europe in May and June 2013. Both workshops were small in terms of the number of participants: 8 and 10. As with Asia, the workshop setup worked well. Participants noted that the time allocated for the workshop (ten hours over two days) was too brief. In one of the workshops the co-trainer from Asia could not participate. Instead the senior project manager in the company (in terms of the longest tenure) was trained to take on the role as opinion leader and contributed to the case projects to look at (bullet 3 in Figure 2)

The workshops were also evaluated using a questionnaire. Table 1 lists the items on this questionnaire.

Table 1. Evaluation questionnaire items

- How important do you believe that project management skills and understanding are in relation to your position?

- Is the PM procedure adequate?

- How well does the approach the workshop takes using a mix of PM theory and exercises work?

- How well does the workshop in your opinion reinforce the use of the PM procedure for ENKACE operations?

- Workshop trainer?

- Workshop material? 
The participants were asked to rate questions on a scale from one to five, with one being poor and five being excellent. On average answers in the three workshops ended up at $4.2-4.3$. The highest scores in the two workshops were given to question no. 4 on how well the workshop reinforced the use of the best practice procedure. Based on the experience and the participant responses, our conclusion is that TPB is suitable as a kernel theory for designing a workshop to diffuse best practice.

The learning that developed from this iteration centered on the role played by the opinion leader. While enlisted as an advocate for change (in order to overcome resistance-to-change), this individual demonstrated how essential it is to situate the best practices within the practical context of the participants. This role must be richer than merely advocating for change, but became as well essential for helping the participants to learn how the best practices would operate in their own context.

\subsection{Iteration Two}

The second iteration and intervention took place in another part of ENKACE. The three workshops in Iteration One covered most of the project managers in that part of the company. This second iteration was then aimed at project managers for land operations in a mature market. The aim of the undertaking was to create buy-in for two of three best practice procedures and to deliver information about a third. Procedures again - had been written by QA based on best practices identified throughout the company. The three procedures regarded: (1) Starting a project; (2) Running a project; and (3) Creating a Project Quality Plan.

Based on the experience from Iteration One, and because three best practice procedures were diffusing, it was decided to add three hours each day making it an 16 hour workshop in total. In order to expand the focus on local context, new topics were covered including stakeholder management and even more emphasis was placed on planning. A new teaching case (with exercises relevant to the context of the new group of project managers) was developed and incorporated. The teaching case allowed the participants to experience a project situation that could easily have been their own project. This new case context was important to give the participants the perception of behavioral control through

The first workshop in Iteration Two was held in August 2013 in North America, the second in September (Europe), a third in October (Europe), and a fourth in the beginning of November again in North America. Learning from the first iteration continued through the workshops in the second iteration. In the first workshop, the new teaching case was not fully successful in building in the participants' own context. More work was needed to attract the participants to picture themselves as working with just such a project. Between the first and the second workshop the teaching case was updated. It was important to get it exactly right so that the participants could picture themselves in it as if it was their own project.

Another limitation concerned the co-trainer's ability to command a role as opinion leader. The co-trainer in Iteration Two had many years' experience in industry but only one year experience in ENKACE. While well-equipped to contextualize a new best practice, this co-trainer lacked corporate-level experience with this particular new practice itself. This clearly led to limitations in the co-trainer's ability to take on the 
role both as opinion leader for the new practice, and as contextualizing expert to help the participants situate the new practice in their own projects.

\subsection{Iteration Three}

In parallel with the latter part of Iteration Two another target group of project managers were identified. This third target population for the best practices was land operations in immature markets. Again, the aim of the workshop was to diffuse the use of best practice procedures, e.g. in dealing with the immature market and the risks incurred by it.

In Iteration Three a very experienced co-trainer with many years at ENKACE was engaged. This co-trainer also took on a more active role in the workshop. Where the division of work in the first two iterations had been $70-30 \%$ between the trainer/researcher and the co-trainer/ENKACE-er, in Iteration Three the division of work was fifty-fifty.

In October 2013, the first instance of Iteration Three opened. The timing was again eight hours a day for two days. The participants fell in two groups; Old with more than 20 years' experience (on average), and Young with about five years' experience (on average).

An interesting observation was that the intended behavior (the buy-in) by the Young group was higher than the Old group. The attitude from some of old group was, "just let me keep doing what I have been doing all the time; why bother with a new best practice procedure? To me my practice is good enough."

Another interesting observation was that the co-trainer had been training some of the Young group four-five years ago when they first came to the company. This history strongly influenced the co-trainer's ability to function as opinion leader among these people. They simply accepted straight away what was being taught as best practice. In contrast, the Old group needed to see several examples before becoming convinced that they were confronting a best practice.

\subsection{The Effect of the Interventions}

In the first iteration there was very clear buy-in (behavioral intention) to the procedure immediately after the workshop. An interesting question is (of course) whether that behavior intention yielded behavioral achievement. (In other words, did this buy-in last?) Preliminary indications are positive. The Iteration One co-trainer observed improved use of the best practice had continued months later. However, no exact figures have been gathered yet. So it is still too early to measure an effect (for example as a lower percentage of failing projects).

In the second iteration there was clear behavioral intention toward two out of three best practices. For the first two instances the buy-in was not directly measured. But then we developed an instrument specifically for measuring buy-in (behavioral intention). The questions asked for the first best practice procedure (on starting projects) are shown in Figure 3. 
I consider the "START" procedure useful (Circle figure)

Strongly disagree 1 $-2$ $-3$ -5 Strongly agree

Don't know

I believe I can use the "START" procedure in my work

Strongly disagree 1 $-2-3-3-3$ -5 Strongly agree

Don't know

Fig. 3. Best practice "buy-in" questions for determining behavioral intention

Similar questions were asked for the "CONTINUE" best practice procedure on ongoing project management and for the Project Quality PLAN procedure.

The buy in for the three procedures after instance 3 (the third best practice) was reasonably good. On a scale from 1 to 5 (with 5 being "Strongly Agree") the scoring is shown in Table 2.

Table 2. Behavior intention (buy-in) for three best practices after instance three

\begin{tabular}{|l|c|c|c|c|c|c|}
\hline N=14 & $\begin{array}{c}\text { START } \\
\text { Useful }\end{array}$ & $\begin{array}{c}\text { START } \\
\text { I can use }\end{array}$ & $\begin{array}{c}\text { CONTINUE } \\
\text { useful }\end{array}$ & $\begin{array}{c}\text { CONTINUE } \\
\text { I can use }\end{array}$ & $\begin{array}{c}\text { PLAN } \\
\text { useful }\end{array}$ & $\begin{array}{c}\text { PLAN } \\
\text { I can use }\end{array}$ \\
\hline Average & 3.57 & 3.57 & 3.46 & 3.54 & 3.71 & 3.71 \\
\hline
\end{tabular}

The buy-in for the three procedures at the end of the training was quite good and noticeably higher than in instance 3 . On a scale from 1 to 5 with 5 being "Strongly Agree" the scoring at the end is shown in Table 3.

Table 3. Behavioral intention (buy-in) at the end of the intervention

\begin{tabular}{|l|c|c|c|c|c|c|}
\hline N=15 & $\begin{array}{c}\text { START } \\
\text { Useful }\end{array}$ & $\begin{array}{c}\text { START } \\
\text { I can use }\end{array}$ & $\begin{array}{c}\text { CONTINUE } \\
\text { useful }\end{array}$ & $\begin{array}{c}\text { CONTINUE } \\
\text { I can use }\end{array}$ & $\begin{array}{c}\text { PLAN } \\
\text { useful }\end{array}$ & $\begin{array}{c}\text { PLAN } \\
\text { I can use }\end{array}$ \\
\hline Average & 4.00 & 3.36 & 3.86 & 3.50 & 4.07 & 3.93 \\
\hline
\end{tabular}

There was a change between workshop instance 3 and workshop instance 4 . We gave the participants an exercise for each best practice/procedure: "Make a critical review of the procedure and come up with at least one observation e.g. on something missing or superfluous". This exercise seems to have a positive influence possibly linked to participants' perception of control over the procedures and ability to influence it.

In the third iteration three instances has taken place. The measured buy-in effect of the first instance workshop was good. Seven out of nine rated the effect "Good", one rated it "Fair, and one rated in "Inadequate". The one rating it inadequate pointed to the lack of relevance of the procedures to the individual himself as the main cause. 
Overall, however, there was a high measured positive effect of the workshop on participant behavioral intention (buy-in) to adopt the best practices.

\section{Discussion}

The learning that developed across iterations one and two shifted our perspective on the essential practical problem. We initially framed the problem as "resistance-tochange". Across the iterations, we reframed this problem as "not-invented-here".

This re-framing arose as the role of the co-trainer evolved. In keeping with Roger's (2003) theory that opinion leaders can help overcome resistance to change, the initial role of the co-trainer was pronounced as an opinion leader. As the iterations evolved, a further critical role emerged: that of contextualizing expert who helped participants see themselves using the new best practice in their own projects. The importance of both roles became evidence in the comparison of the iterations. In iteration one, the co-trainer was both opinion leader and contextualizing expert. In iteration one, the outcome of the TPB-based training program was positive. In iteration two, the co-trainer was well prepared as an opinion leader, but a weakly prepared as a contextual expert. The outcome of the TPB-based training program was less positive. In iteration three, the co-trainer was more carefully chosen to strongly suit both roles. The outcome of the TPB-based training program was very positive.

The research question at hand is, "Why do organizations fall victim to the innate problems with diffusion of best practices?" Our work first reveals that there are two essential innate problems involving behavioral planning: (1) resistance-to-change, and (2) not-invented-here. Problem one is a deeply human issue involving both psychological and cognitive components. Grounding training in TPB provides an avenue to resolving this problem. In our research setting, however, the second problem is also a facet of decentralized organizations. It is a tension between centricity and diversity in the sense that widespread adoption of best practices assumes sufficient organizational coherence to permit distributed adoption of the practice. But in decentralized organizations, such an assumption may only hold in the most central part of the organization. Diffusion of a best practice requires the engagement of experts who can help adopters situate the practice in their own specific context. Such experts address the not-invented-here problem but do not obviate the resistance-to-change problem. Also needed are opinion leaders.

Organizations fall victim to innate problems of diffusion of best practices because there is a problem dualism confronting such diffusion: resistance-to-change and notinvented-here. Such diffusion is aided when both opinion leaders and contextualizing experts are engaged in the process.

The results reported in this paper has some likeliness to the work of Mathiassen et al. [18] on Software Process Improvement. In Chapter 1 they discuss how important it is to focus on real problems to motivate improvements [18, p. 4]. That is exactly the mechanism used in the workshops at ENKACE. Mathiassen et al. [18, p. 11] also emphasizes that "Participation makes improvement happen" which is exactly why it was so successful involving co-trainers in the workshop. 


\section{Conclusion}

Research that considers the nature of best practices and in particular the diffusion of best practices is remarkably sparse. This may lead to a critical suspicion that the diffusion of best practice is difficult or nearly impossible. However, at the core of being professional often lies the notion of being able to apply best practices. In that sense professionals are knowledge carrying agents across or within organizations.

In this paper we have described an Action Case study with the aim of using TPB as the kernel theory for a design of a method for diffusing best practices within the case organization ENKACE. In short we found that it is possible to use TPB for guiding a design. And we found that the resulting design actually diffused best practice within ENKACE. In more detail we found:

Diffusion of best practices can be motivated as part of a professional identity within an organization especially through the systematic engagement of opinion leaders to influence subjective norm.

It is important to allow the described best practice to be adopted into the community of practice that contextualizes the practices. One possible vehicle for achieving this diffusion is the discussion of lessons learned from relevant, completed projects.

Lessons learned from prior projects can be used for co-constructing a practice building on the best practice - in a new setting with different actors. Internal stickiness that makes the diffusion costly is hard to avoid. But using TPB as kernel theory for the design can help considerably.

Best practice diffusion often involves a dependence upon the transfer of primarily explicit knowledge. But the transfer of implicit aspects is also an important part of working professionally. Actors in the field are not just receivers of a best practice, but are co-constructors of this best practice. The workshop design applied here (cf. Figure 2) allowed for this.

Furthermore, our findings from ENKACE indicate that the match between the practice and the context materialized in the presence of two concordant factors. On the context side, the qualities of the selected co-trainer / opinion leader were necessary to provide the subjective norm described in TPB. On the best practice side, the technological qualities of the best practice itself were necessary to instill the ideal attitude (belief that the behavior will be effective). These two factors were especially critical if the source context of the best practice is qualitatively different from the target context into which the organization is seeking to diffuse the best practice.

\section{References}

1. Ungan, M.C.: Manufacturing best practices: Implementation success factors and performance. Journal of Manufacturing Technology Management 18(3), 333-348 (2007)

2. Teodoro, M.P., Hughes, A.G.: Socializer or Signal?, How Agency Accreditation Affects Organizational Culture. Public Administration Review 72(4), 583-591 (2012)

3. Carr, C., Pudelko, M.: Convergence of Management Practices in Strategy, Finance and HRM between the USA, Japan and Germany. International Journal of Cross Cultural Management: CCM 6(1), 75-100 (2006) 
4. Creplet, F., et al.: Consultants and experts in management consulting firms. Research Policy 30(9), 1517-1535 (2001)

5. Gooderham, P.N., Nordhaug, O., Ringdal, K.: Institutional and Rational Determinants of Organizational Practices: Human Resource Management in European Firms. Administrative Science Quarterly 44(3), 507-531 (1999)

6. Gonnering, R.S.: The Seductive Allure Of "Best Practices": Improved Outcome Is A Delicate Dance Between Structure And Process. Emergence: Complexity and Organization 13(4), 94-101 (2011)

7. Komporozos-athanasiou, A., et al.: Policy as a struggle for meaning: disentangling knowledge translation across international health contexts. Knowledge Management Research \& Practice 9(3), 215-227 (2011)

8. Dooley, K.J., Subra, A., Anderson, J.: Adoption Rates and Patterns of Best Practices in New Product Development. International Journal of Innovation Management 6(1), 85 (2002)

9. Szulanski, G.: Exploring internal stickiness: Impediments to the transfer of best practice within the firm. Strategic Management Journal 17, 27-43 (1996)

10. Hargrave, T.J., Van De Ven, A.H.: A Collective Action Model of Institutional Innovation. Academy of Management Review 31(4), 864-888 (2006)

11. Walls, J.G., Widmeyer, G.R., El Sawy, O.A.: Building an information system design theory for vigilant EIS. Information Systems Research 3(1), 36-59 (1992)

12. Fishbein, M., Ajzen, I.: Belief, attitude, intention, and behavior: An introduction to theory and research 1975. Addison-Wesley, Reading (1975)

13. Ajzen, I., Fishbein, M.: Understanding attitudes and predicting social behavior. Englewood Cliffs, Prentice-Hall (1980)

14. Ajzen, I.: Theory of planned behavior. In: Van Lange, P.A.M., Kruglanski, A.W., Higgins, E.T. (eds.) Handbook of Theories of Social Psychology, pp. 438-459. Sage (2011)

15. Ajzen, I.: The theory of planned behavior. Organizational Behavior and Human Decision Processes 50(2), 179-211 (1991)

16. Braa, K., Vidgen, R.: Interpretation, intervention, and reduction in the organizational laboratory: a framework for in-context information system research. Accounting, Management and Information Technologies 9(1), 25-47 (1999)

17. Rogers, E.M.: Diifusion of Innovations, 5th edn. The Free Press, New York (2003)

18. Mathiassen, L., Pries-Heje, J., Ngwenyama, O. (eds.): Improving Software Organizations. From Principles to Practice. Addison-Wesley, Boston (2002) 